\title{
Changing the Demographic Characteristics of Males with Erectile Dysfunction During the Coronavirus Disease-2019 Pandemic: A Multi- institutional Comparative Analysis with the Non-pandemic Period
}

\author{
${ }^{1}$ Manisa City Hospital, Clinic of Urology, Manisa, Turkiye \\ 2 İzmir Metropolitan Municipality Eşrefpaşa Hospital, Clinic of Urology, İzmir, Turkiye \\ ${ }^{3}$ Çiğli Regional Training Hospital, Clinic of Urology, İzmir, Turkiye \\ ${ }^{4}$ Ödemiş State Hospital, Clinic of Urology, Izmir, Turkiye \\ 5 Medifema Hospital, Clinic of Urology, Izmir, Turkiye \\ 6izmir Can Hospital, Clinic of Urology, Izmir, Turkiye \\ ${ }^{7}$ Dokuz Eylül University Faculty of Medicine, Department of Urology, İmir, Turkiye \\ ${ }^{8}$ Balıkesir University Faculty of Medicine, Department of Urology, Balıkesir, Turkiye \\ ${ }^{9}$ Celal Bayar University Faculty of Medicine, Department of Urology, Manisa, Turkiye
}

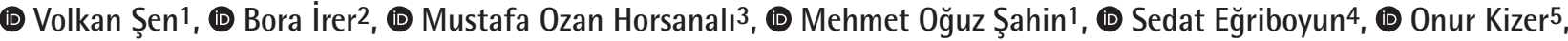

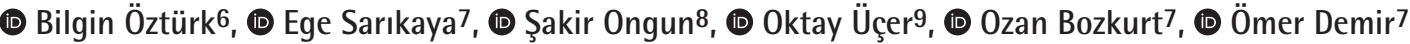

\section{What's known on the subject? and What does the study add?}

Coronavirus disease-2019 has negatively affected sexual life, as well as all life aspects. Most of the studies were commentary or review articles, and only a few studies were designed as research articles that were based on online questionnaires. To the best of our knowledge, this study is one of the few clinical studies that compared the data of the pandemic period and normal period in literature. We revealed that patients who presented with erectile dysfunction (ED) during the pandemic period were younger, with milder ED symptoms.

\section{Abstract}

Objective: This study aimed to present the impact of coronavirus disease-2019 pandemic on seeking treatment in patients with erectile dysfunction (ED) and compare the clinical characteristics, demographics, and laboratory analysis of patients with ED during and before the pandemic period.

Materials and Methods: The clinical and demographic characteristics and laboratory analysis of patients with ED were compared between the time interval of March 9, 2020, to June 1, 2020, and the previous 3 months from the pandemics. The International Index of Erectile Function-5 questionnaire was used to assess ED and the results from two groups were compared.

Results: A 76.4\% decreased total number of outpatient clinics and a 70.9\% decreased number of patients with ED was observed; however a significant increase was detected in the ratio of patients with ED to the total number of patients during the pandemic period $(1.7 \%$ vs. $2.1 \%$, $p=0.008$ ). The median age of patients was smaller in the pandemic period. Mild ED was significantly higher in the pandemic period and moderate ED was detected higher in the period before the pandemic.

Conclusion: The admission rate of patients with ED has increased in the pandemic period. The patients presenting with ED during the pandemic period were younger, with milder ED symptoms.

Keywords: Erectile dysfunction, testosterone, COVID-19, coronavirus, SARS-CoV2

Correspondence: Volkan Şen MD, Manisa City Hospital, Clinic of Urology, Manisa, Turkiye

Phone: +90 5533896859 E-mail: sen_volkan@yahoo.com ORCID-ID: orcid.org/0000-0003-2832-0682

Received: 13.04 .2021 Accepted: 29.05 .2021

Cite this article as: Şen V, İrer B, Horsanalı MO, Şahin MO, Eğriboyun S, Kizer O, Öztürk B, Sarıkaya E, Ongun Ş, Üçer O, Bozkurt O, Demir Ö. Changing the Demographic Characteristics of Males with Erectile Dysfunction During the Coronavirus Disease-2019 Pandemic: A Multi-institutional Comparative Analysis with the Non-pandemic Period. J Urol Surg, 2022;9(1):57-62.

oCopyright 2022 by the Association of Urological Surgery / Journal of Urological Surgery published by Galenos Publishing House. 


\section{Introduction}

Erectile dysfunction (ED) is defined as the persistent inability to attain and maintain an erection sufficient to permit satisfactory sexual performance (1). ED is a worldwide health problem that is increasing with aging, with negative impacts on the quality of life among males (2). The prevalence of ED in the age group of 40-70 years old was reported between $25 \%-52 \%$ in literature (3-6). The pathophysiology of ED may be classified as anatomical, neurogenic, vasculogenic, drug-induced, hormonal, and/or psychogenic. Disasters like the coronavirus disease-2019 (COVID-19) pandemics lead to an increased psychological burden, a result of both fear from the disease and problems caused by social isolation. This psychological burden can negatively affect the erectile functions in males.

COVID-19 was firstly reported in Wuhan, Hubei province of China, and the World Health Organization declared COVID-19 as a pandemic on March 11, $2020(7,8)$. The worldwide total cases reached 110,974,862 and the total deaths reached 2,460,792 (9). The first case was reported on March 11, 2020, and the actual number of cases and deaths from COVID-19 are 353,426 and 9,513, respectively, in Turkey (9). During the COVID-19 pandemic, the workload of hospitals has increased and several healthcare measures were taken by hospital systems and governments. Many of the hospitals have turned to quarantine or pandemic hospitals and had to serve solely patients with COVID-19. The number of outpatient clinics of urology has been decreased and elective surgeries have been canceled $(9,10)$. Hence, the practice of sexual medicine has been dramatically impacted, as most procedures and consultations are essentially elective. Some articles evaluated the challenges in the practice of sexual medicine in the COVID-19 era in literature (11-15). Most of the studies were commentary or review articles, only a few studies were designed as research articles that were based on online questionnaires (11-16). This study aimed to present the impact of the COVID-19 pandemic on seeking treatment in patients with ED and compare the clinical characteristics, demographics, and laboratory analysis of patients with ED between the pandemic period and before the pandemic period. To the best of our knowledge, this study is one of the few clinical studies that compared the data of pandemic and normal period in the literature.

\section{Materials and Methods}

This study was approved by the local ethics committee and included a total of nine centers (Dokuz Eylül University - approval number: 2020/19-22, date: 17.08.2020). The total outpatient clinics and the number of patients with ED were retrospectively recorded. The clinical and demographic characteristics (age, body mass index, smoking, comorbidities, etc.) and laboratory analysis [total testosterone, glucose, prolactin, low-density lipoprotein (LDL), high-density lipoprotein, and total cholesterol] of patients with ED were compared between the time interval of March 9, 2020, (the first patient with COVID-19 was reported in Turkey) to June 1,2020, and the previous 3 months from the pandemics, December 16, 2019, to March 9, 2020. The International Index of Erectile Function-5 (IIEF-5) questionnaire was used to assess ED and the results from the two groups were compared. According to total IIEF-5 scores, the score of 26-30 means no ED, 22-25 as mild $E D, 17-21$ as mild-moderate $E D, 11-16$ as moderate $E D$, and $0-10$ as severe ED. The severity of ED was also compared between the groups.

\section{Statistical Analysis}

The Statistical Package for the Social Sciences software version 25.5 (IBM, NY, USA) was used for analyses. The KolmogorovSmirnov and Shapiro-Wilk normality tests were used to state the continuous normally distributed data. The chi-square test was used for the comparison of categorical data and the MannWhitney $\mathrm{U}$ test to compare parameters that were not normally distributed. Results were given as median [(minimum (min)maximum (max)], number, and percentage (\%). P-values of $<0.05$ were considered statistically significant.

\section{Results}

The total number of outpatient clinics was 40,631 in the period before the pandemics and 9,604 in the pandemic period. The number of patients with ED was 694 in the period before the pandemics and 202 in the pandemic period. A 76.4\% decreased total number of outpatient clinics and a 70.9\% decreased number of patients with ED was observed; however, a significant increase was detected in the ratio of patients with ED to the total number of patients during the pandemic period ( $1.7 \%$ vs. $2.1 \%, p=0.008)$. The median age of patients who were admitted during the pandemic period were smaller than the period before the pandemic, and their body mass index was found to be significantly higher [45 $(\min =20-\max =74)$ years vs. $46(\mathrm{~min}=18-\mathrm{max}=79)$ years, $\mathrm{p}=0.043 ; 27.2(\mathrm{~min}=20.7-$ $\max =38.5) \mathrm{kg} / \mathrm{m}^{2}$ vs. $26.4(\min =18.7-\max =36.2) \mathrm{kg} / \mathrm{m}^{2}, p<0.001$; respectively]. Smoking rates were significantly detected higher in the pandemic period (55.4\% vs. $43.5 \%$ ). When the severity of ED was compared between the groups; mild ED was significantly higher in the pandemic period ( $4.5 \%$ vs. $0.9 \%$ ) and moderate ED was higher before the pandemic (Figure 1). The comparison of the two groups in terms of demographics and clinical characteristics was presented in Table 1. According to laboratory analysis, the median values of LDL, total cholesterol, and total testosterone were significantly lower in the pandemic period (Table 2). 


\section{Discussion}

COVID-19 has negatively affected sexual life, as well as all life aspects. Some reports were published about the challenges in the practice of sexual medicine in the COVID-19 era from several countries (11-15). Li et al. (11) evaluated the changes in people's sexual behavior during the COVID-19 pandemic with an online survey, that was applied to 189 females and 270 males in China and revealed a significant decline in frequency and

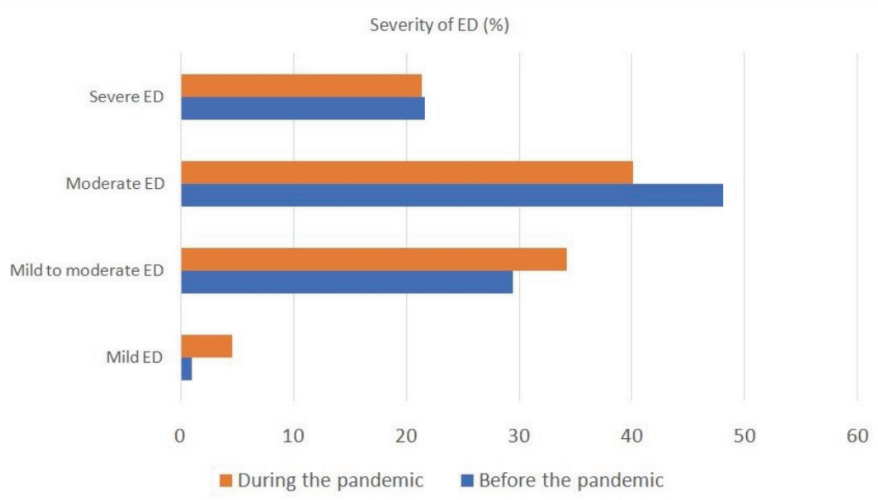

Figure 1. Comparison of ED severity between the pandemic period and the period before the pandemic

ED: Erectile dysfunction overall sexual activity. Jacob et al. (12) investigated the level of sexual activity during the COVID-19 social distancing and selfisolation measures in the UK with an online survey. A total of 868 individuals responded to an online survey, $63.1 \%$ of them were females and the prevalence of sexual activity was $<40 \%$. They detected a significant correlation between the lower sexual activity and older adults, female gender, and unmarried status (12). Schiavi et al. (17) assessed the effects of the social distancing measures during the COVID-19 pandemic on the quality of life and sexual function of reproductive-age females. The individuals previously answered the Female Sexual Distress Scale (FSDS), the 36-Item Short Form Survey (SF-36), and the Female Sexual Function Index (FSFI) questionnaires. After 4 weeks from the restrictive measures, the same questionnaires were filled out by individuals via e-mail. A total of 89 females were included in their study and they revealed significant decreases in the mean sexual intercourses/month $(6.3 \pm 1.9$ vs. $2.3 \pm 1.8)$, the mean FSFI scores $(29.2 \pm 4.2$ vs. $19.2 \pm 3.3)$, and SF36 scores $(82.2 \pm 10.2$ vs. $64.2 \pm 11.8)$. Additionally, a significant increase was found in the FSDS scores $(9.3 \pm 5.5$ vs. $20.1 \pm 5.2)$ and concluded that the COVID-19 pandemic and the restrictive social distancing measures have negatively influenced the quality of life and sexual function in females. Most of the published research studies were online survey based studies

Table 1. The comparison of the demographics and clinical characteristics of patients with erectile dysfunction between the pandemic period and the period before the pandemic

\begin{tabular}{|c|c|c|c|}
\hline & $\begin{array}{l}\text { Period before the pandemic } \\
\text { (December 16, 2019-March 9, 2020) } \\
n=694\end{array}$ & $\begin{array}{l}\text { Pandemic period } \\
\text { (March 9, 2020-June 1, 2020) } \\
n=202\end{array}$ & $\mathbf{p}$ \\
\hline Age, median (years) (min-max) & $46(18-79)$ & $45(20-74)$ & 0.043 \\
\hline $\begin{array}{l}\text { BMI, median }\left(\mathrm{kg} / \mathrm{m}^{2}\right) \\
(\min -\max )\end{array}$ & $26.4(18.7-36.2)$ & $27.2(20.7-38.5)$ & $<0.001$ \\
\hline Smoking $(n, \%)$ & $302(43.5 \%)$ & $112(55.4 \%)$ & 0.003 \\
\hline $\begin{array}{l}\text { Smoking, (package year), median } \\
\text { (min-max) }\end{array}$ & $0(0-50)$ & $20.0(0-55)$ & 0.279 \\
\hline Alcohol $(n, \%)$ & $50(7.2 \%)$ & $11(5.4 \%)$ & 0.382 \\
\hline Hypertension $(n, \%)$ & $222(32.0 \%)$ & $45(22.3 \%)$ & 0.008 \\
\hline Diabetes mellitus $(\mathrm{n}, \%)$ & $172(24.8 \%)$ & $39(19.3 \%)$ & 0.106 \\
\hline Coronary heart disease $(n, \%)$ & $117(16.9 \%)$ & $17(8.4 \%)$ & 0.003 \\
\hline Hypertension $(n, \%)$ & $106(15.3 \%)$ & $31(15.3 \%)$ & 0.980 \\
\hline Hyperthyroidism $(n, \%)$ & $6(0.9 \%)$ & $0(0.0 \%)$ & 0.185 \\
\hline Hypothyroidism $(n, \%)$ & $4(0.6 \%)$ & $2(1.0 \%)$ & 0.526 \\
\hline Psychiatric $(n, \%)$ & $24(3.5 \%)$ & $9(4.5 \%)$ & 0.508 \\
\hline IIEF, median (min-max) & $14(7-25)$ & $15(7-25)$ & 0.005 \\
\hline \multicolumn{4}{|l|}{ Severity of ED $(n, \%)$} \\
\hline Mild ED & $6(0.9 \%)$ & $9(4.5 \%)$ & $<0.001$ \\
\hline Mild to moderate ED & $204(29.4 \%)$ & 69 (34.2\%) & 0.195 \\
\hline Moderate ED & $334(48.1 \%)$ & $81(40.1 \%)$ & 0.044 \\
\hline Severe ED & $150(21.6 \%)$ & $43(21.3 \%)$ & 0.921 \\
\hline
\end{tabular}


that evaluated the impacts of the COVID-19 pandemic on the sexual health of individuals $(11,12,17)$, and several commentaries were published on COVID-19 and sexual health (13-15). However, the literature reported insufficient data on the changes in the management of patients with ED in the COVID-19 era. Thus, this study aimed to present the impact of the COVID-19 pandemic on seeking treatment in patients with ED and compare the clinical characteristics, demographics, and laboratory analysis of patients with ED between the pandemic period and before the pandemic period. Our study revealed that the rate of patients with ED who seek treatment has increased during the pandemic period, consistent with the studies which presented the negative effects of the COVID-19 pandemic on sexual life.

The prevalence of obesity is increasing worldwide and is reported as $>20 \%$ in almost all countries $(18,19)$. Several measures started to be taken in all countries due to the COVID-19 pandemic like restriction in movement, social distancing, self-isolation, and impeding economic activities across a broad spectrum of nonessential occupations (20). Most of the individuals who had an opportunity for remote working worked from their homes without physical activity. These measures also led to some changes in food consumption and a decrease in physical activity, which may have a role in weight gain (20). As expected, the body mass index values of patients with ED in the COVID-19 period were higher than the non-pandemic period in our study.

The COVID-19 outbreak negatively affects the mental health of the population and increases the likelihood of illnesses, such as anxiety and depression, getting worse (21). Worsening mental health and stress were reported as predisposing factors for increased smoking, frequency, and quantity, as well as relapse $(21,22)$. Likewise, the literature revealed that the smoking rates were also higher in patients with ED during the COVID-19 pandemic in our study.

Many studies showed that the prevalence and ED severity increased with aging $(23,24)$. Martins and Abdo (25) reported that younger patients with ED ( $<40$ years) are more likely to have mild ED with a rate of $73.7 \%$. Yang et al. (26) pointed out that young patients with ED had higher incidences of anxiety and depression. The median age of patients with ED was lower and the rate of mild ED was higher in the pandemic period compared with before the pandemic period in our study. Therefore, the studies revealed that the physiological factors likely more affect the younger patients and seem to be related with more mild ED severity.

ED is closely related to diabetes mellitus (DM), hypertension (HT), dyslipidemia, and metabolic syndrome, and with aging, the rates of all these comorbidities increases (1-4). Additionally, some studies reported the association between ED severity and coronary arterial disease $(27,28)$. Al-Daydamony et al. (27) detected that patients with moderate and severe ED (IIEF-5 score of $<17$ ) had a significantly higher risk of coronary artery diseases than mild ED. Garcia-Cruz et al. (28) reported that the presence and severity of ED correlated with the presence of HT, DM, dyslipidemia, and the number of cardiovascular risk factors. Patients with ED before the pandemic period were older and had more moderate ED in our study. Consistent with the literature, higher LDL and total cholesterol values and higher $\mathrm{HT}$ and coronary arterial disease rates were detected in these patients.

$\mathrm{Ma}$ et al. (29) compared the sex-related hormones of 119 reproductive-aged male patients with COVID-19 with 273 age-matched un-infected males and revealed that the serum total testosterone levels were significantly lower in patients with COVID-19. Studies do not support a consistent association between testosterone level and mood. There may be some males in whom hypogonadism contributes to depression; and chronic depressive illness may cause hypogonadism in some (30). The serum testosterone levels were lower in a patient with ED during the pandemic period in our study. The possible causes may be related to COVID-19 or psychological disorders, which can affect testosterone levels. However, further studies are needed to clarify this relationship.

Table 2. The comparison of the laboratory analysis of patients with erectile dysfunction between the pandemic period and before the pandemic period

\begin{tabular}{|c|c|c|c|}
\hline & $\begin{array}{l}\text { Period before the pandemic } \\
\text { (December 16, 2019-March 9, 2020) } \\
n=694\end{array}$ & $\begin{array}{l}\text { Pandemic period } \\
\text { (March 9, 2020-June 1, 2020) } \\
n=202\end{array}$ & $\mathbf{p}$ \\
\hline LDL, median (min-max) & $127(38-229)$ & $110(28-241)$ & $<0.001$ \\
\hline HDL, median (min-max) & $44(21-144)$ & 40 (14-95) & 0.440 \\
\hline Total cholesterol, median (min-max) & $206(85-586)$ & $190(108-400)$ & $<0.001$ \\
\hline Total testosterone, median (min-max) & $434(41-1098)$ & $370(11-835)$ & $<0.001$ \\
\hline Prolactin, median (min-max) & $10.0(0.1-95.0)$ & $9.3(1.4-95.0)$ & 0.913 \\
\hline
\end{tabular}




\section{Study Limitations}

The main limitations are its retrospective design and the lack of standardized psychological evaluation with questionnaires. However, the strongest part of the study was being one of the few clinical studies that compared the data of pandemic period and normal period of patients with ED in the literature.

\section{Conclusion}

COVID-19 negatively affected the sexual life of individuals. While a serious decrease was observed in the rates of application to outpatient clinics for many urological diseases, the application rate of ED patients has increased in the pandemic period. Patients presenting with ED during the pandemic period were younger, with milder ED symptoms.

\section{Ethics}

Ethics Committee Approval: This study was approved by the local ethics committee and included a total of nine centers (Dokuz Eylül University - approval number: 2020/19-22, date: 17.08.2020).

Informed Consent: Retrospective study.

Peer-review: Externally peer-reviewed.

\section{Authorship Contributions}

Surgical and Medical Practices: V.Ş., Concept: V.Ş., Design: V.Ş., Data Collection or Processing: V.Ş., B.I., M.O.H., M.O.Ş., S.E., O.K., B.Ö., E.S., S..O., O.Ü., O.B., Ö.D., Analysis or Interpretation: V.Ş., B.I.., M.O.H., M.O.Ş., S.E., O.K., B.Ö., E.S., Ş.O., O.Ü., O.B., Ö.D., Literature Search: V.Ş., Writing: V.Ş.

Conflict of Interest: No conflict of interest was declared by the authors.

Financial Disclosure: The authors declare that they have no relevant financial.

\section{References}

1. Hatzimouratidis K, Giuliano F, Moncada I, A. Muneer, A. Salonia, P. Verze Guideline Associates: A. Parnham, E.C. Serefoglu. EAU Guidelines on Erectile Dysfunction, Premature Ejaculation, Penile Curvature and Priapism. Edn. presented at the EAU Annual Congress London 2017. Publisher: EAU Guidelines Office. Place published: Arnhem, The Netherlands.

2. Fisher WA, Eardley I, McCabe M, Sand M. Erectile dysfunction (ED) is a shared sexual concern of couples I: couple conceptions of ED. J Sex Med 2009;6:2746-2760.

3. Zhang $X$, Yang B, Li N, Li H. Prevalence and Risk Factors for Erectile Dysfunction in Chinese Adult Males. J Sex Med 2017;14:1201-1208.

4. Braun $M$, Wassmer $G$, Klotz $T$, Reifenrath $B$, Mathers M, Engelmann U. Epidemiology of erectile dysfunction: results of the 'Cologne Male Survey'. Int J Impot Res 2000;12:305-311.
5. Quilter M, Hodges L, von Hurst P, Borman B, Coad J. Male Sexual Function in New Zealand: A Population-Based Cross-Sectional Survey of the Prevalence of Erectile Dysfunction in Men Aged 40-70 Years. J Sex Med 2017;14:928936.

6. Nguyen HMT, Gabrielson AT, Hellstrom WJG. Erectile Dysfunction in Young Men-A Review of the Prevalence and Risk Factors. Sex Med Rev 2017;5:508520 .

7. Bogoch II, Watts A, Thomas-Bachli A, Huber C, Kraemer MUG, Khan K. Pneumonia of unknown aetiology in Wuhan, China: potential for international spread via commercial air travel. J Travel Med 2020;27:taaa008.

8. World Health Organization. Coronavirus disease 2019 (COVID-19) Situation Report -51 [Internet]. 11 March. 2020 [cited 2020 May 25]. Available from: https://www.who.int/docs/default-source/coronaviruse/situationreports/20200311-sitrep-51-covid-19.pdf?sfvrsn=1 ba62e57_10.

9. WHO Coronavirus Disease (COVID-19) Dashboard. [Internet]. 22 Feb. 2021 [cited 2021 FEB 22]. Available from: https://covid19.who.int/.

10. Bozkurt O, Sen V, Irer B, Sagnak L, Onal B, Tanidir Y, Karabay E, Kaya C, Ceyhan E, Baser A, Duran MB, Suer E, Celen I, Selvi I, Ucer O, Karakoc S, Sarikaya E, Ozden E, Deger D, Egriboyun S, Ongun S, Gurboga O, Asutay MK, Kazaz IO, Yilmaz IO, Kisa E, Demirkiran ED, Horsanali 0, Akarken I, Kizer O, Eren H, Ucar M, Cebeci 00, Kizilay F, Comez K, Mercimek MN, Ozkent MS, Izol V, Gudeloglu A, Ozturk B, Akbaba KT, Polat S, Gucuk A, Ziyan A, Selcuk B, Akdeniz F, Turgut H, Sabuncu K, Kaygisiz O, Ersahin V, Kahraman HI, Guzelsoy M, Demir 0; Study Group of the Society of Urological Surgery. Nation-wide analysis of the impact of Covid-19 pandemic on daily urology practice in Turkey. Int J Clin Pract 2021;75:e13735.

11. Li W, Li G, Xin C, Wang Y, Yang S. Challenges in the Practice of Sexual Medicine in the Time of COVID-19 in China. J Sex Med 2020;17:1225-1228.

12. Jacob L, Smith L, Butler L, Barnett $Y$, Grabovac I, McDermott D, Armstrong N, Yakkundi A, Tully MA. Challenges in the Practice of Sexual Medicine in the Time of COVID-19 in the United Kingdom. J Sex Med 2020;17:1229-1236.

13. Miranda EP, Nascimento B, Torres LO, Glina S. Challenges in the Practice of Sexual Medicine in the Time of COVID-19 in Brazil. J Sex Med 2020;17:12221224.

14. Shindel AW, Rowen TS. Challenges in the Practice of Sexual Medicine in the Time of COVID-19 in the United States. J Sex Med 2020;17:1216-1219.

15. Torremade J, Martinez-Salamanca J. Challenges in the Practice of Sexual Medicine in the Time of COVID-19 in Spain. J Sex Med 2020;17:1220-1221.

16. Cocci A, Giunti D, Tonioni C, Cacciamani G, Tellini R, Polloni G, Cito G, Presicce F, Di Mauro M, Minervini A, Cimino S, Russo Gl. Love at the time of the Covid-19 pandemic: preliminary results of an online survey conducted during the quarantine in Italy. Int J Impot Res 2020;32:556-557.

17. Schiavi MC, Spina V, Zullo MA, Colagiovanni $V$, Luffarelli $P$, Rago $R$, Palazzetti P. Love in the Time of COVID-19: Sexual Function and Quality of Life Analysis During the Social Distancing Measures in a Group of Italian Reproductive-Age Women. J Sex Med 2020;17:1407-1413.

18. NCD Risk Factor Collaboration (NCD-RisC). Rising rural body-mass index is the main driver of the global obesity epidemic in adults. Nature 2019;569:260-264.

19. NCD Risk Factor Collaboration (NCD-RisC). Trends in adult body-mass index in 200 countries from 1975 to 2014: a pooled analysis of 1698 population-based measurement studies with $19 \cdot 2$ million participants. Lancet 2016;387:1377-1396.

20. Popkin BM, Du S, Green WD, Beck MA, Algaith T, Herbst CH, Alsukait RF, Alluhidan M, Alazemi N, Shekar M. Individuals with obesity and COVID-19: A global perspective on the epidemiology and biological relationships. Obes Rev 2020;21:e13128.

21. Patwardhan P. COVID-19: Risk of increase in smoking rates among England's 6 million smokers and relapse among England's 11 million ex-smokers. BJGP Open 2020;4:bjgpopen20X101067. 
22. Stubbs B, Veronese $N$, Vancampfort $D$, Prina AM, Lin PY, Tseng PT, Evangelou E, Solmi M, Kohler C, Carvalho AF, Koyanagi A. Perceived stress and smoking across 41 countries: A global perspective across Europe, Africa, Asia and the Americas. Sci Rep 2017;7:7597.

23. Feldman HA, Goldstein I, Hatzichristou DG, Krane RJ, McKinlay JB. Impotence and its medical and psychosocial correlates: results of the Massachusetts Male Aging Study. J Urol 1994;151:54-61.

24. Laumann EO, Paik A, Rosen RC. Sexual dysfunction in the United States: prevalence and predictors. JAMA 1999;281:537-544.

25. Martins $\mathrm{FG}$, Abdo $\mathrm{CHN}$. Erectile dysfunction and correlated factors in Brazilian men aged 18-40 years. J Sex Med 2010;7:2166-2173.

26. Yang $Y$, Song $Y, L u Y, X u Y, L i u L, L i u X$. Associations between erectile dysfunction and psychological disorders (depression and anxiety): A crosssectional study in a Chinese population. Andrologia 2019;51:e13395.
27. Al-Daydamony MM, Shawky A, Tharwat A. Erectile dysfunction severity as a predictor of left main and/or three-vessel disease in acute coronary syndrome patients. Indian Heart J 2018;70 Suppl 3:S56-S59.

28. Garcia-Cruz E, Piqueras $M$, Gosálbez D, Pérez-Márquez $M$, Peri L, Izquierdo L, Franco A, Luque P, Corral JM, Alvarez-Vijande R, Alcaraz A. La disfunción eréctil y su severidad están en relación con el número de factores de riesgo cardiovascular [Erectile dysfunction and its severity are related to the number of cardiovascular risk factors]. Actas Urol Esp 2012;36:291-295.

29. Ma L, Xie W, Li D, Shi L, Ye G, Mao Y, Xiong Y, Sun H, Zheng F, Chen Z, Qin J, Lyu J, Zhang Y, Zhang M. Evaluation of sex-related hormones and semen characteristics in reproductive-aged male COVID-19 patients. J Med Virol 2021;93:456-462.

30. Amiaz R, Seidman SN. Testosterone and depression in men. Curr Opin Endocrinol Diabetes Obes 2008;15:278-283. 